\title{
Microdeposition of amyloid in the joints
}

\author{
Y. A. GOFFIN, Y. THOUA, AND P. R. POTVLIEGE \\ From the Department of Pathological Anatomy, Hôpital Brugmann, Université Libre de Bruxelles
}

SUMMARY The distribution of amyloid in various organs, including the hip and the sternoclavicular joints, was systematically investigated in a prospective necropsy study of 91 unselected individuals whose median age was 70 years. The overall incidence of amyloid microdeposits in both joints was $56 \%$. Their presence correlated significantly with age only. The deposition began earlier in the sternoclavicular joint, where the fibrocartilaginous disc was almost exclusively affected. The myocardium was the next most frequently affected organ, with an incidence of $12 \cdot 2 \%$. Minor amyloidosis of the articular tissues had no significant clinical counterpart, neither was it associated with any particular disease. It seemingly represents a localised and isolated degenerative phenomenon, whose morphological aspects invite speculation about the pathogenic role of long-lasting mechanical stress.

During the last 2 decades several reports on amyloid involvement of articular and periarticular tissues have appeared. Two forms may be distinguished according to the importance of amyloid deposition and its clinical consequences. Large deposits are responsible for a disease that simulates rheumatoid arthritis. ${ }^{1-824}$ This form is rare, has its highest prevalence in the 4th and 5th decades of life, and generally is associated with myeloma or forms part of a generalised amyloid disease. Any joint may be involved, and the involvement is usually symmetrical. Destructive intraepiphyseal nodules have been

Accepted for publication 4 January 1980

Correspondence to Dr Y. A. Goffin, Department of Pathological Anatomy, Hôpital Brugmann, Université Libre de Bruxelles, 1020 Brussels, Belgium. described by Uehlinger. ${ }^{5}$ Cartilage plates and fibrocartilage may be affected. ${ }^{2}$

Microscopic deposits which characterise the asymptomatic form are commoner. ${ }^{9-11}$ These have been discovered in the capsules of the hip joints of patients operated upon for degenerative osteoarthritis as well as in post-mortem specimens taken from elderly people who had no clinical evidence of joint disease.

Such deposits are generally held to represent a very limited type of amyloid disease, which is entirely devoid of clinical significance. However, this opinion needs to be confirmed, since it is based on pathological studies which up to now were limited to the joints. In the present investigation the tissues of 2 different types of joints were systematically

Table 1 Subjects and tissue sampling

\begin{tabular}{llll}
\hline a. Age group $(y r)$ & No. of subjects & $\begin{array}{l}\text { b. Diseases (other than } \\
\text { amyloidosis) }\end{array}$ \\
\hline $0-19$ & 3 & Cardiovascular diseases \\
$20-39$ & 8 & Chronic inflammatory & po. subjects \\
& & processes & 15 \\
$40-59$ & 23 & Malignant tumours & 13 \\
$60-79$ & 34 & Cirrhosis & 8 \\
Over 80 & 23 & Diabetes & 7 \\
& & Chronic gastroduodenal ulcers & 7 \\
& & Miscellaneous & 15
\end{tabular}

\begin{tabular}{ll} 
Brain: & c. Tissues examined \\
$\begin{array}{ll}\text { Oral mucosa: } \\
\text { Thyroid }\end{array}$ & $\begin{array}{l}\text { misc. } \\
\text { gum or tongue }\end{array}$ \\
Heart: & interauricular septum, ventricle, His bundle, \\
Pancreas: & $\begin{array}{l}\text { mitral and aortic valves } \\
\text { tail }\end{array}$ \\
\hline
\end{tabular}

(single section each)
Spleen:
Kidney:
Colon:
Sternoclavicular
joint:
Hip joint:

including capsule cortex and medulla pelvic part, whole thickness

capsule and fibrocartilagenous disc fibrous capsule and synovium 
examined for the presence of amyloid: the capsule of the hip, a diarthrodial joint, and the capsule together with the fibrocartilaginous disc of the sternoclavicular joint, an amphiarthrodial joint. Visceral tissues were also explored in the same random group of 91 subjects seen at necropsy.

The incidence of asymptomatic amyloid deposits of the joints, together with its relationship to age and its association to nonarticular amyloid deposition as well as to other diseases are the subject of this report.

\section{Material and methods}

Tissues were obtained post mortem from 91 subjects admitted to the different departments of the Brugmann University Hospital during the period 1976-8. The only selection consisted in the exclusion from the study of these cases in which the post-mortem interval exceeded $24 \mathrm{~h}$.

The age distribution is recorded in Table 1a and the diseases other than amyloidosis in Table $1 \mathrm{~b}$. Tissue samples, listed in Table 1c, were fixed in $10 \%$

Table 2 Fifty subjects with amyloid deposits

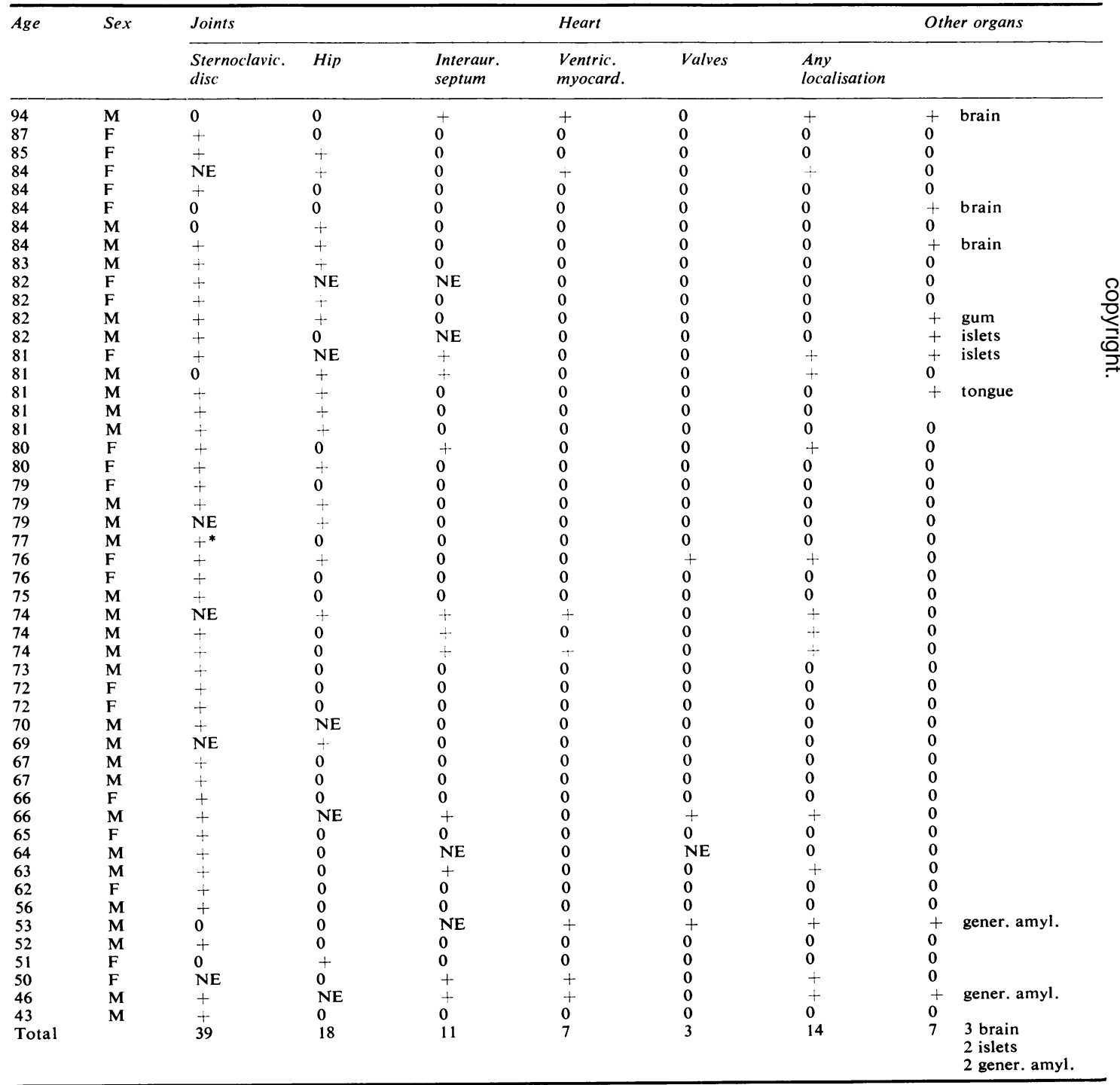

*Ultrastructural study. $\mathrm{NE}=$ not examined. 
formaldehyde and processed to paraffin. The sections were stained with haematoxylin-erythrosin-saffron and for the detection of amyloid with Congo red and thioflavin $\mathrm{T}$. The sections of the 15 first cases were also stained by the SAB (sodium sulphate alcian blue) method of Lendrum et al. ${ }^{12}$ Material was identified as amyloid only if it showed the characteristic Congo red apple green colour under polarised light. In a few cases the Congo red staining was preceded by potassium permanganate oxidation. ${ }^{13}$ In one case, a Congo red positive deposit in the sternoclavicular

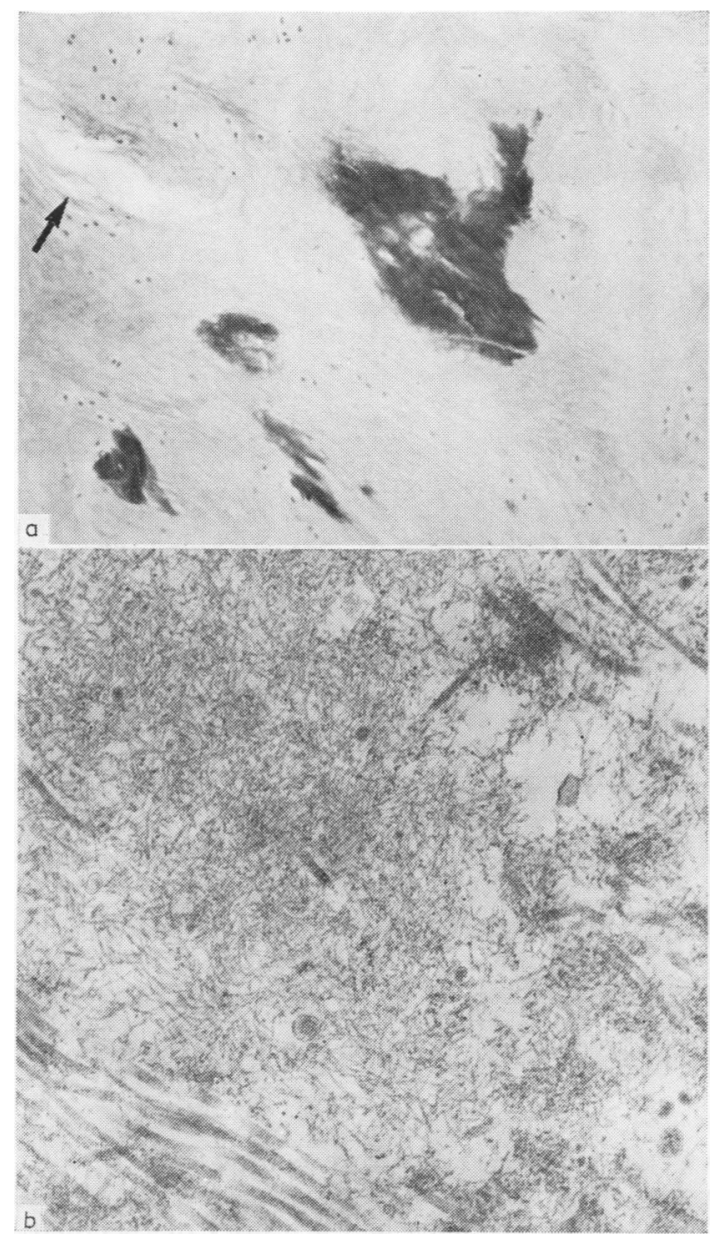

Fig. 1 Amyloid deposits in fibrocartilage from sternoclavicular disc in a 77-year-old male. (a) Congo red stain under unpolarised light. $(\times 27)$. Note area of fibrillation (arrow). (b) Electron micrograph. Haphazardly disposed microfibrils infiltrate a bundle of collagenous fibrils. The ultrastructure is typical for amyloid. (Uranium acetate lead citrate; $\times 36000$ ). joint was processed for electron microscopy, as indicated in Table 2.

\section{Results}

\section{TOPOGRAPHY AND FORM OF AMYLOID}

DEPOSITS

As is shown in Table 2, the organs most frequently affected were the sternoclavicular joint (39 cases), the hip joint (18 cases), and the heart (14 cases).

In the sternoclavicular joint the structure almost exclusively involved was the avascular fibrocartilaginous disc. The fibrous capsule was affected in only 1 case and then in association with the disc. The main site of deposition was the central part of the disc, in no obvious relationship to the connective tissue cells, and in areas of fibrillation (Fig. 1a). In severe cases the central part of the disc showed fragmentation (Fig. 2) and it was sometimes infiltrated by an alcian blue-positive mucoid substance. The amyloid deposits could be clearly distinguished from neighbouring minute foci of brightly eosinophilic and congophilic material that showed no green birefringence and presumably represented areas of degenerated ground substance. In the 1 case where electron microscopy was performed on a diseased disc typical ultrastructural features of amyloid were observed (Fig. 1b). In the hip joint the amyloid deposits were of microscopic size and confined to the fasciculated and dense fibrous tissue of the capsule. They had no relationship with blood vessels (Fig. 3). In 2 out of 18 positive cases the joint was also affected by arthrosis, and in 1 of these the amyloid deposits were particularly abundant. However, massive accumulation consistent with a nodular form of so-called amyloid joint disease was never observed.

In the heart the structure mainly affected was the myocardium, with an incidence of $12 \%$, and the interauricular septum as the predominant localisation. In the 50 cases where conductive tissue was examined it was found to be consistently free of deposits. Valvular involvement was rare, being noticed in only 3 out of 86 mitral and 90 aortic valves. In 12 out of 14 cases of cardiac amyloidosis there were associated amyloid deposits in the hip joint, the sternoclavicular disc, or both.

Permanganate oxidation of the sections did not alter the staining reaction of the articular and cardiac deposits of amyloid. Other localisations were infrequent. Amyloid was present in the islets of 2 pancreas specimens, in the sigmoid mucosa of only 1 case ( 1 of the patients with generalised amyloidosis), in the oral mucosa of 3 out of 51 investigated specimens, and in the brain of 3 out of 36 examined specimens. 


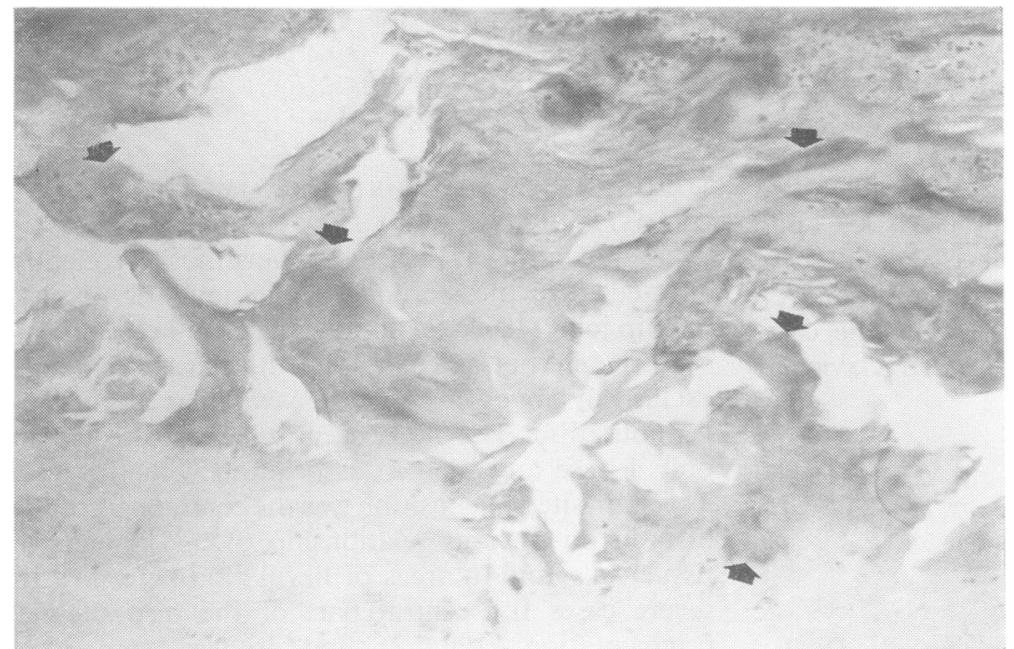

Fig. 2 Amyloid deposits (arrows) in an area of severely fragmented fibrocartilage of the sternoclavicular disc in a 63-year-old male. (Congo red $\times 11)$.

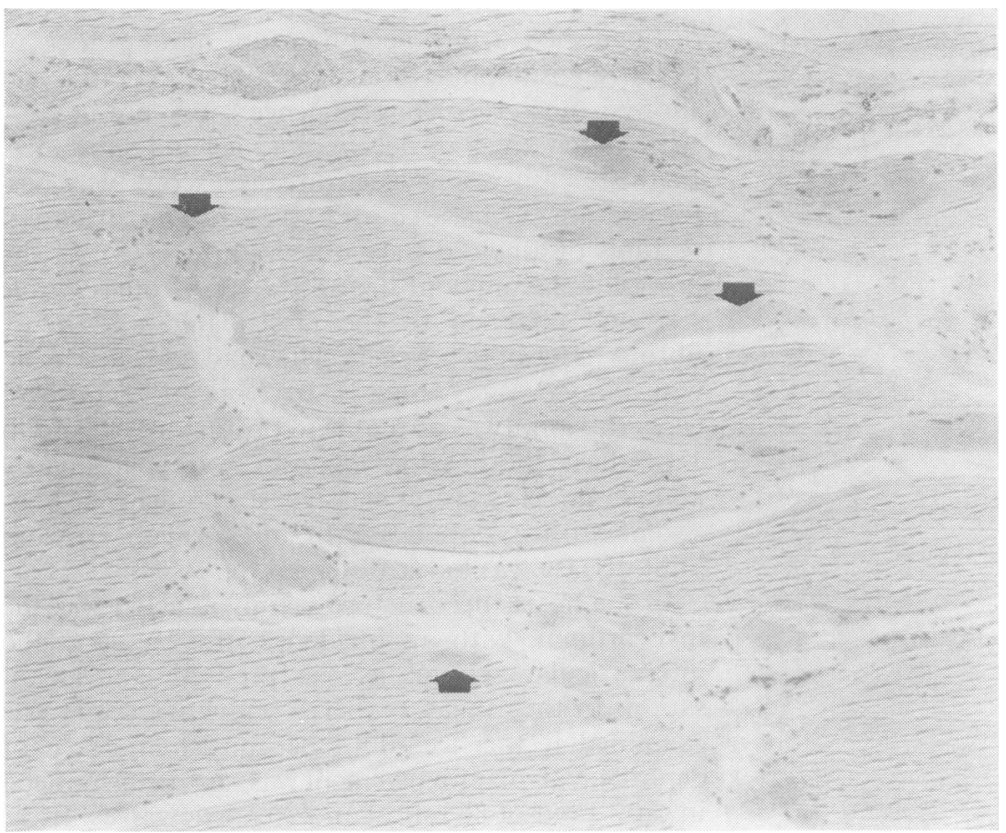

Fig. 3 Capsule of the hip joint in a 74-year-old male. Multiple amyloid deposits (arrows) are scattered among bundles of collagen. (Congo red; $\times 11$ ).

AMYLOID DEPOSITION AND AGE

As shown in Tables 3 and 4 and Fig. 4, there was a highly significant correlation between advancing age and the presence of small amyloid deposits in articular tissues and mycocardium. They were found in approximately 1 out of 6 hip joint capsules and in 2 out of 3 sternoclavicular discs in the group of patients aged from 60 to 79 years, and those proportions rose to respectively $3 / 5$ and $3 / 4$ in patients over 79 years.

\section{ARTICULAR AMYLOID DEPOSITS AND} ASSOCIATED DISEASES

Only 3 of our patients had a history of rheumatological disease. Two of them were 79-year-old males with arthrosis of the hip. Microscopic deposits of amyloid were seen in their hip joints; the sternoclavicular disc was examined in 1 of these individuals and was found to be involved. The myocardium was spared. One 40-year-old male had a history of rheumatoid arthritis: no amyloid deposits were 
Table 3 Overall incidence of amyloid in various organs and tissues, grouped according to age

\begin{tabular}{|c|c|c|c|c|c|c|c|c|c|c|c|c|c|c|}
\hline \multirow{2}{*}{$\begin{array}{l}\text { Age } \\
\text { (years) }\end{array}$} & \multicolumn{14}{|c|}{ Number positive for amyloid/total number of patients examined } \\
\hline & $\begin{array}{l}\text { Any } \\
\text { organ }\end{array}$ & $\begin{array}{l}\text { Sterno- } \\
\text { cl. disc }\end{array}$ & Hip & $\begin{array}{l}\text { IAS. } \\
\text { heart }\end{array}$ & $\begin{array}{l}\text { Ventr. } \\
\text { myoc. }\end{array}$ & $\begin{array}{l}\text { Heart } \\
\text { valves }\end{array}$ & $\begin{array}{l}\text { Pancreas } \\
\text { islets }\end{array}$ & Brain & $\begin{array}{l}\text { Oral } \\
\text { muc. }\end{array}$ & Spleen & Liver & Kidney & Thyroid & Colon \\
\hline $0-39$ & $0 / 11$ & $0 / 11$ & $0 / 9$ & $0 / 11$ & $0 / 11$ & $0 / 11$ & $0 / 11$ & $0 / 5$ & $0 / 1$ & $0 / 11$ & $0 / 11$ & $0 / 11$ & $0 / 11$ & $0 / 11$ \\
\hline $40-49$ & $1+1 * / 10$ & $1+1 * / 8$ & $0 / 10$ & $1 * / 10$ & $1 * / 9$ & $0 / 10$ & $0 / 10$ & $0 / 3$ & $1 * / 7$ & $0 / 10$ & $0 / 10$ & $0 / 10$ & $1 * / 10$ & $1 * / 10$ \\
\hline $50-59$ & $4+1^{*} / 13$ & $2 / 10$ & $1 / 13$ & $1 / 12$ & $1+1 * / 13$ & $1 * / 13$ & $0 / 13$ & $0 / 5$ & $0 / 9$ & $1 * / 13$ & $1 * / 13$ & $1 * / 12$ & $1 * / 13$ & $0 / 13$ \\
\hline $60-69$ & $9 / 11$ & $8 / 10$ & $1 / 10$ & $2 / 10$ & $0 / 11$ & $1 / 10$ & $0 / 11$ & $0 / 5$ & $0 / 3$ & $0 / 11$ & $0 / 11$ & $0 / 11$ & $0 / 11$ & $0 / 11$ \\
\hline $70-79$ & $14 / 23$ & $12 / 21$ & $4 / 21$ & $3 / 22$ & $2 / 23$ & $1 / 22$ & $0 / 23$ & $0 / 9$ & $0 / 15$ & $0 / 23$ & $0 / 23$ & $0 / 23$ & $0 / 23$ & $0 / 23$ \\
\hline $80-89$ & $17 / 22$ & $15 / 21$ & $12 / 18$ & $3 / 21$ & $1 / 22$ & $0 / 22$ & $2 / 22$ & $2 / 8$ & $2 / 15$ & $0 / 22$ & $0 / 22$ & $0 / 22$ & $0 / 22$ & $0 / 21$ \\
\hline Over 89 & $1 / 1$ & $0 / 1$ & $0 / 1$ & $1 / 1$ & $1 / 1$ & $0 / 1$ & $0 / 1$ & $1 / 1$ & $0 / 0$ & $0 / 1$ & $0 / 1$ & $0 / 1$ & $0 / 1$ & $0 / 1$ \\
\hline Total & $46+2 * / 91$ & $39 / 82$ & $18 / 82$ & $11 / 87$ & $7 / 90$ & $2+1 * / 88$ & $2 / 91$ & $3 / 36$ & $3 / 51$ & $1 * / 91$ & $1 * / 91$ & $1 / 90$ & $2 * / 91$ & $1 * / 90$ \\
\hline
\end{tabular}

*Cases of systemic amyloidosis. IAS =interauricular septum.

Table 4 Relationship of age to presence of amyloid

\begin{tabular}{|c|c|c|c|c|c|c|c|c|c|c|c|c|}
\hline \multirow{2}{*}{$\begin{array}{l}\text { Organ or tissue } \\
\text { Any organ/tissue }\end{array}$} & \multirow{2}{*}{$\begin{array}{l}\text { Total no. } \\
\text { patients } \\
\text { examined }\end{array}$} & \multicolumn{2}{|c|}{$\begin{array}{l}0-19 y r \\
A+\text { number } \\
\text { of patients }\end{array}$} & \multicolumn{2}{|c|}{$\begin{array}{l}20-39 \text { yr. } \\
\text { A+ number } \\
\text { of patients }\end{array}$} & \multicolumn{2}{|c|}{$\begin{array}{l}40-59 \text { yr. } \\
\text { A+ number } \\
\text { of patients }\end{array}$} & \multicolumn{2}{|c|}{$\begin{array}{l}60-79 y r . \\
A+\text { number } \\
\text { of patients }\end{array}$} & \multicolumn{2}{|c|}{$\begin{array}{l}\text { Over } 79 \text { yr. } \\
\text { A+ number } \\
\text { of patients }\end{array}$} & \multirow{2}{*}{$\begin{array}{l}\begin{array}{l}P \text { value } \\
\text { (chi-square) }\end{array} \\
0.001\end{array}$} \\
\hline & & 0 & 3 & 0 & 8 & $6\left(+1^{*}\right)$ & 23 & 23 & 34 & 20 & 23 & \\
\hline Heart & 91 & 0 & 3 & 0 & 8 & $\left(2+1^{*}\right)$ & 23 & 5 & 34 & 5 & 23 & 0.005 \\
\hline Hip joint capsule & 81 & 0 & 2 & 0 & 7 & 1 & 21 & 5 & 31 & 12 & 20 & 0.001 \\
\hline Sternoclav. disc & 84 & 0 & 3 & 0 & 8 & 4 & 20 & 20 & 31 & 15 & 22 & 0.001 \\
\hline Both joints & 80 & 0 & 2 & 0 & 7 & 0 & 20 & 2 & 31 & 9 & 20 & 0.001 \\
\hline
\end{tabular}

*Systemic amyloidosis. $\mathrm{A}=$ amyloid.
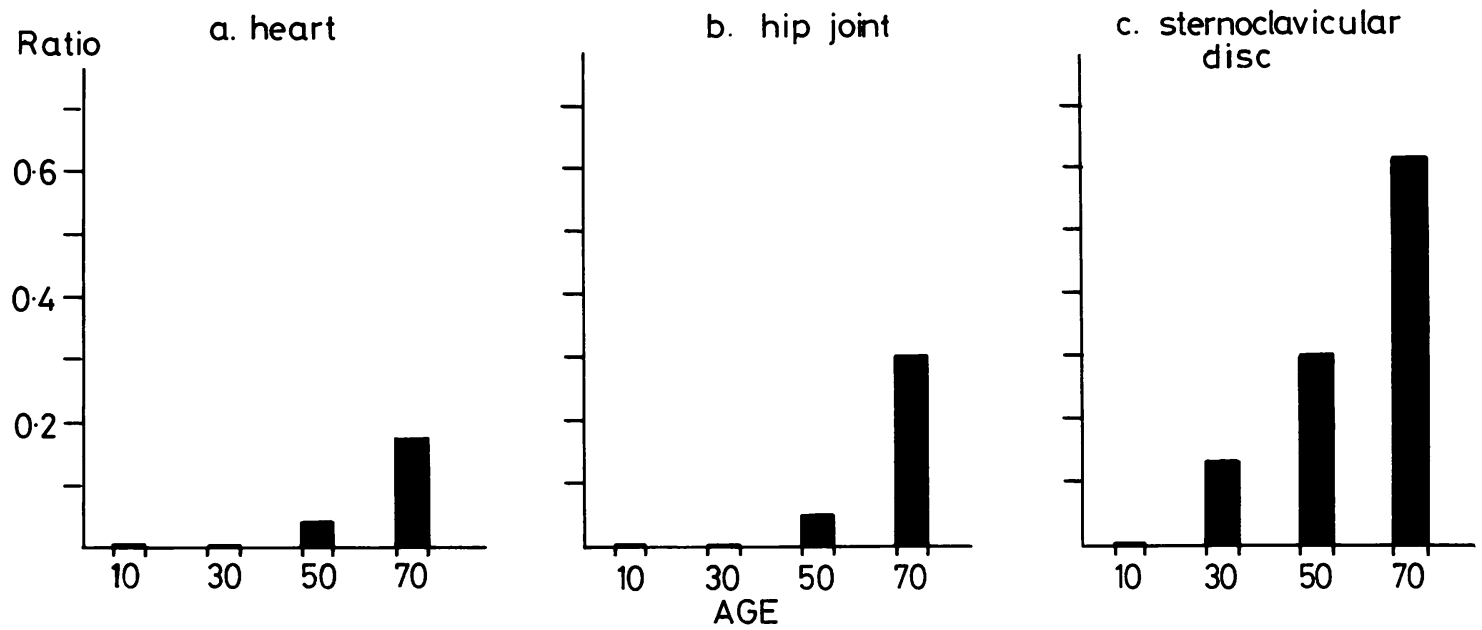

Fig. 4 Histograms showing the relationship of age to the presence of amyloid in (a) heart; (b) hip joint; (c) sternoclavicular disc.

discovered at necropsy. Generalised amyloidosis was present in 2 male patients, aged respectively 53 and 46 years. The former had died from progressive renal failure due to massive amyloidosis of the kidneys; the spleen liver, pancreas, thyroid, and heart were also involved, but the joints were spared. The latter had a long-standing history of tuberculosis of the lung and sacroiliac joint followed by suppurative bronchiectases; amyloid deposits were found in the thyroid, colon mucosa, tongue, myocardium, and sternoclavicular disc.
Cancer was present in 13 patients whose ages ranged from 46 to 85 years (median 68). The primary site was in the bronchus in 3 cases and in 7 others in the digestive tract. One other patient had a monoclonal gammopathy but no overt myeloma was discovered at necropsy. The incidence of amyloid deposits in this group was not significantly different from that observed in all other patients. In the monoclonal gammopathy the sternoclavicular disc and the myocardium were involved.

Eight patients had cirrhosis of the liver. The 
incidence of amyloid deposits differed in no way from that observed in the general population of our patients.

Three of our cases had clinically apparent diabetes mellitus but none showed amyloidosis of the pancreatic islets.

\section{Discussion}

Our investigation was based on the necropsy findings recorded in an unselected population of 91 individuals with a median age of 70 years. Its main results were the following.

The overall incidence of microdeposits of amyloid in the joint tissues reached the surprisingly high figure of $56 \%$.

The only significant correlation was with age. The incidence of positive findings rose steadily from $0 \%$ in individuals aged less than 39 years to $22 \%$ in the group aged from 40 to 59 years and to $77 \%$ in the people aged more than 59 years. There also was a different overall incidence of involvement between the 2 joints which were systemically examined. In the hip joint it reached $22 \%$ as compared to $47.5 \%$ in the sternoclavicular joint. The difference was entirely due to a greater frequency of sternoclavicular involvement beneath the age of 79 years.

The presence of amyloid deposits in the myocardium was also systematically investigated. Its incidence was considerably less, reaching $16 \%$. However, a comparable correlation with old age was found. Out of 13 cases with amyloidosis of the myocardium only 3 had no simultaneous joint involvement. Among the latter, 1 was an instance of generalised amyloidosis of the primary type.

In no case had the articular microdeposits of amyloid been the cause of clinically apparent joint disease.

The topography of the deposits differed among the 2 joints that were systematically examined. In the hip the capsule was affected, whereas in the sternoclavicular joint the deposits occurred almost exclusively in the disc.

Our findings are complemented by those of Ravid et al., ${ }^{14}$ who likewise made a necropsy study of the incidence of amyloid micro-deposits, this time in internal organs. Their material comprised 391 individuals with no overt generalised amyloidosis, whose median age approximated 60 years. Localised deposits were discovered in $18.4 \%$ of all cases. The adenohypophysis headed the list of affected organs with an incidence of $37.5 \%$, whereas the heart was involved in only $2.6 \%$. The incidence of amyloid microdeposition in internal organs also steadily rose with age, reaching a maximum of $36 \%$ beyond the age of 70 . With the notable exception of diabetes mellitus of late onset, which correlated with pancreatic islet amyloidosis, there was no consistent clinical disease which could be attributed to intravisceral microdeposition of amyloid.

The similarities with our own findings are striking and help to define minor amyloidosis as a very common and usually asymptomatic feature of senescence. As regards the nature of the amyloid protein which is deposited in this condition, its presence in small amounts and its variable distribution among organs render the chemical identification difficult. Oxidation by acidified potassium permanganate prior to Congo red staining was advocated by Wright et al. ${ }^{13}$ as a histochemical tool helpful in distinguishing different forms of amyloid. The amyloid which is predominantly composed of protein AA and appears in so-called secondary amyloidosis seemingly is the only one which loses Congo red affinity and green dichroism following permanganate treatment. We applied this method to some of the positive cases and found the amyloid deposits to be uniformly permanganateresistant. Such negative result is one additionalo similarity with the amyloid of so-called seniles cardiac amyloidosis.

One of our findings which deserves special comment is the peculiar topography of the joint deposits. When amyloid was present in either the hip capsule or the sternoclavicular disc, it was never seen in close proximity to blood vessels, synovial surface, fibrous cells, or chondrocytes. It was deposited within the ground substance of fibrous and fibrocartilaginous tissues, where it was interspersed with collagen fibres and elastic membranes.

Bywaters and Dorling ${ }^{2}$ have suggested that a soluble amyloid precursor may diffuse from the synovial fluid into the articular cartilage, possibly along preformed but hitherto unknown pathways. Such a pathogenetic mechanism seemingly does not apply to the sternoclavicular joint, where the amyloid deposits were electivally situated in the central part of the disc in relation to areas of fibrillary transformed cartilage. This observation, together with the relatively early appearance of amyloid in the sternoclavicular joint, invites speculation about the pathogenetic role of long-lasting mechanical stresses. The sternoclavicular joint is indeed a poorly movable articulation in which microscopic 'fatigue fractures' could easily arise, in the same way as they do in tendons. An additional argument in favour of this view may be found in the frequent presence of microscopical amyloid deposits within severely damaged and scarred heart valves. ${ }^{15}$

Such a hypothesis agrees with the view that 
favourable local conditions are required to trigger off amyloid precursors conversion and deposition in the tissues. ${ }^{16}$ The exact nature of precursors in the case of amyloid microdeposits in joints is unknown, but, according to Glenner and Page, ${ }^{17}$ those of the localised type of amyloidosis, in order to be able to permeate far beyond the capillary walls, should be small and monomeric molecules.

To what extent microdeposition of amyloid impairs joint function of elderly people is difficult to assess. From the clinical records of our patients, however, there was nothing to suggest that the positive cases suffered from any particular rheumatologic ailment.

The heart was the second most frequent localisation of minor senile amyloidosis encountered in our material. The histological appearance and distribution of the deposits are in agreement with those generally reported. ${ }^{18-22}$ The myocardium and endocardium were most frequently involved, in contrast to the valves, which were rarely affected. The infiltration was slight to moderate and was in no case consistent with a restrictive cardiomyopathy or a massive nodular valulopathy. No deposits were discovered in 50 investigated sections of the His bundle, and this result was in accordance with the report of Rudolfi et al., ${ }^{23}$ who showed that the most striking finding in a group of patients with different degrees of heart amyloidosis was the relative sparing of the specialised conduction tissue.

In conclusion, it appears that asymptomatic amyloid deposition in the joints is not associated with any pathological condition either generalised or localised. On the contrary it constitutes an isolated degenerative phenomenon related to age. With regard to the so-called 'modern clinical classification of human amyloid deposits and amyloidosis' proposed by Glenner and Page, ${ }^{17}$ it should be introduced in the group of the 'localised deposition of amyloid', since the lesions are present without the production of easily recognisable clinical abnormalities.

The authors are indebted to Professor W. Hijmans for his constructive criticism, to Dr J. J. Vanderhaeghen, who examined the brain specimens of this series, to Mr V. Van Cleerhout for his technical assistance, and to Mrs S. Pieters for typing the manuscript.

\section{References}

1 Goldberg A, Brodsky I, McCarty D. Multiple myeloma with paramyloidosis presenting as rheumatoid disease. Am J Med 1964; 37: 653-8.

2 Bywaters E G L, Dorling J. Amyloid deposits in articular cartilage. Ann Rheum Dis 1970; 29: 294-306.
3 Wiernik P H. Amyloid joint disease. Medecine 1972; 51 : 465-79.

4 Gordon D A, Pruzanski W, Ogryzlo M A, Little H A. Amyloid arthritis simulating rheumatoid disease in five patients with multiple myeloma. Am J Med 1973; 55: 142-54.

5 Uehlinger E. Destruktive Gelenkamyloidose (Amyloidarthrose). Verhältnis des Deutsches Gesellschaft für Rheumatismus 1974; 3: 233-8.

6 Buhtz P, Mölleken K. Generalisierte Amyloidose mit Arthropathie. Z Inn Med 1974; 29: 294-306.

7 Villiaumey J, Larget-Piet B, Pointeud P. Les complications articulaires de la maladie de Hahler. Rev Rhum Mal Osteoartic 1975; 42: 25-34.

8 Fondimare A, Boumard M C, Deshayes P. Amylose pseudo-tumorale articulaire et juxta-articulaire accompagnant un myélome. Rev Rhum Mal Osteoartic 1976; 43: $144-5$.

9 Sørensen K H, Christensen H E. Local amyloid formation in the hip joint capsule in osteoarthritis. Acta Orthop Scand 1973; 44: 460-6.

10 Mohr W. Amyloid deposits in the periarticular tissue. $Z$ Rheumatol 1976; 35: 412-7.

11 Goffin $Y$, Dedoncker E. Altérations histologiques et histochimiques de la capsule articulaire dans l'arthrose et chez les sujets séniles. Rev Rhum Mal Osteoartic $1980 ; 47: 15-20$.

12 Lendrum A C, Slidders W, Fraser D S. Renal hyaline: A study of amyloidosis and diabetic fibrinous vasculosis with new staining methods. J Clin Pathol 1972; 25: 373-96.

13 Wright $J$ R, Calkins E, Humphrey $R$ L. Potassium permanganate reaction in amyloidosis. A histologic method to assist in differentiating forms of this disease. Lab Invest 1977; 36: 274-81.

14 Ravid M, Gafni J, Sohar E, Missmahl H P. Incidence and origin of non-systemic microdeposits of amyloid. J Clin Pathol 1967; 20: 15-20.

15 Goffin Y. Microscopic amyloid deposits in the heart valves: a common local complication of chronic damage and scarring. J Clin Path in press.

16 Pruzanski W. Amyloidogenesis: theories and facts (editorial). J Rheumatol 1977; 4: 219-28.

17 Glenner G G, Page D L. Amyloid, amyloidosis and amyloidogenesis. In Richter G W, and Epstein M A, eds. International Review of Experimental Pathology. Academic Press: New York, San Francisco, London: Academic Press, 1976; 15: 1-81.

18 Pomerance A. The pathology of senile cardiac amyloidosis J Pathol Bacteriol 1966; 91: 357-67.

19 Wright J R, Calkins E, Breen W J, Stolte G, Schultz R T. Relationship of amyloid to aging. Medecine 1969; 48: $39-60$.

20 Buja L M, Khoi N B, Roberts W C. Clinically significant cardiac amyloidosis. Clinicopathological findings in 15 patients. Am J Cardiol 1970; 26: 394-405.

21 Stiller D, Katenkamp D. Die senile amyloidose des Herzens. Dtsch Gesundheitswesen 1971; 26: 2178-83.

22 Juillet Y, Grogogeat Y. L'amylose cardiaque: aspects cliniques, radiologiques, electriques, hémodynamiques, évolutifs et anatomiques, Arch Mal Coeur 1977; 4: 361-70.

23 Rudolfi R L, Bulkley B H, Hutchins G M. The conduction system in cardiac amyloidosis. $A m \mathrm{~J}$ Med 1977; 62: 677-86.

24 Nashel D J, Widerlite L W, Pekin T J. IgD myeloma with amyloid arthropathy. Am J Med 1973; 55: 426-30. 